allows only one hand to be free I had a small nasal clamp made which might be fixed immediately after removal of the face-piece.

This modification of Mr. Coxon's method has been even more successful in our hands than the original plan, and with Mr. Madin's kind help I demonstrated its application at the annual meeting of the Central Counties Branch of the British Dental Association, held at Worcester on July 9th, Mr. Surman of that city being good enough to find a suitable patient. This demonstration very well illustrated the prolongation of anæsthesia by this modified method. The subject, a woman of ordinary type and about thirty years of age, needed the removal of eleven teeth, nine in the upper and two in the lower jaw. including many stumps. After the insertion of a Brunton's gag between the jaws and in the middle line full anæsthesia was induced in the ordinary way by means of Hewitt's apparatus, and when the face-piece was removed the oral tube was quickly substituted for it and inserted by Mr. Madin into the corner of the mouth away from the operator, while I manually compressed the nares and allowed a stream of nitrous oxide to pass from a gas-bag kept moderately distended through the tube, endeavouring to merely keep the mouth full of the gas. An uninterrupted and perfect anæsthesia was obtained, characterised by slight cyanosis of the face and lips and by quietly snoring breathing. The mouth tube was so well manipulated that it did not at all embarrass Mr. Malcolm Knott, the dental surgeon, who was operating with deliberation, especially in the extraction of the last few teeth. The duration of operation was two and a half minutes, and after it had been finished the anæsthesia was prolonged for another half-minute for the purpose of further demonstrating the ease of maintaining it as long as might be necessary. During the latter part of the operation the Brunton's gag was changed for that of Mason. The operator would have done very well indeed to have extracted all the teeth in two ordinary sittings for gas.

This was a most successful case for a demonstration, the patient being well under throughout without movement of any kind, slightly cyanosed as regards colour, her breathing being easy and rather snoring in character. The operator was very pleased with the result. Recovery of the patient was extremely rapid and not marked by any untoward symptom-indeed, was exactly like that after the usual halfminute anæsthesia. The quantity of nitrous oxide used was about 48 gallons and supposing that 8 gallons (which is perhaps a little above the average for an adult) were used in inducing full narcosis, then only 8 gallons were used for each extra half-minute of anæsthesia, a quantity which is considerably less than that used in the same time by Mr. Coxon's original method. For, supposing the nasal passages to remain open and manipulation to be going on in the mouth, there is a tendency for the patient, even in the case of mouth-breathers, to breathe wholly through the nose and the inhaled nitrous oxide is very largely diluted with air in the pharynx, while during expiration and the pause between expiration and the following inspiration there is free vent through the nares for the escape of the gas as well as of air If the nostrils be blocked much gas is obviously saved, and as possibly some reflex hindrance (induced by the oral interference) to free respiration still exists, the breathing is for a short time at any rate quieter and less frequent, and if the mouth be simply kept full of nitrous oxide it can well be effected that enough gas is inhaled to maintain full anæsthesia, while it is diluted with a not too large quantity of air.

In suitable cases the duration of the anæsthesia may be determined only by the conclusion of operative interference. Where it is possible digital has an advantage over instrumental compression of the nares, in that it gives one more command over the head and can be applied very easily at any period of the anæsthesia, while it is sometimes difficult to quickly apply or reapply a clamp with one hand. One or two chief points for guidance in the use of this modified method have already been indicated, but the last and not the least remains to be noted and concerns the question of an assistant to the anæsthetist. In any dental operatior. where more than a few teeth have to be extracted under gas in the ordinary way a dexterous speed is necessary on the part of the operator, and it is ofter advisable for him to have an assistant who shall help him in the matter of sponging, handing instruments, \&c., but if this method of prolonging anæsthesia be adopted the operator car take his time and do his own sponging and the assistant (if only three persons besides the patient be present) may help the anæsthetist, for it is a very great advantage to have some one to change the facepiece for the mouth-tube and if skilled to insert and manage the tube while the administrator concerns himself with more serious matters, such as the condition of the patient and degree of anæsthesia, the command of the head and jaws, the manipulation of the gag, the closure of the nares, the gas-supply, and watches that no blood or foreign bodies be allowed to remain in the mouth. 'The tube I use has an internal diameter of about $\frac{1}{2}$ in., is made to fit my Hewitt's gas apparatus, and can be carried in the pocket. The advantages of the method are obvious. It is extremely simple and adaptable, needing no cumbrous, complicated, or novel apparatus, and can be effectively applied to probably the large majority of patients who can take gas in the usual way, doing away with the need for many a second sitting for extraction, saving time and trouble to both patient, anæsthetist, and operator, and also perhaps sparing the patient the mental discomfort of anticipating a second administration. I use the modified method in most cases (at the Dental Hospital) requiring a longer anæsthesia than usual.

The disadvantage of the method is that it needs some prac. tice on the part of the anæsthetist and also on the part of the assistant, if one be present, to successfully keep the tube out of the way of the operator. I do not think, as I said earlier, that for really long or severe dental operations the original method of Mr. Coxon or this modified one will or ought to replace the administration of gas and ether, but both should hold a place midway between the ordinary gas inhalation on the one hand and the use of gas followed by ether on the other.

Birmingham.

\section{THE DIAGNOSIS OF HYSTERO-EPILEPSY FROM STATUS EPILEPTICUS.}

\section{BY WILFRED R. KINGDON, B.S., M.B. DURH.,}

RESIDENT MEDICAL OFFICER OF THE TICEHURST ASYLUM, SUSSEX ; LATE ASSISTANT MEDICAL OFFICER TO THE MALE SIDE OF THE BIRMINGHAM CITY ASYLUM.

WE are indebted to French writers, and especially to Professor Charcot, for the more important descriptions of hystero-epilepsy; indeed, the condition appears to be much more frequently found on the continent than in England. When met with in the Anglo-Saxon race this disease seems to be not infrequently of such a type as to be easily mistaken for status epilepticus by those who are unaccustomed to see epilepsy in its severer forms, and for this reason I venture to think that some short account of two cases which it has been my fortune to see during the past two years will not be altogether without interest.

CASE 1.-About sixteen months ago I saw a young woman, seventeen years of age, who was supposed to suffer from epilepsy and who had had that morning what was said to be "status." She was of a highly neurotic family, two or three relatives were described as "hysterical," and, if I remember rightly, a grandfather had attempted his life and ended his days in a lunatic asylum. The patient had been what some would call "over-educated," but which I would prefer to describe as improperly educated-in fact, " crammed." I elicited after some difficulty the following facts concerning the "status" which was said to have taken place. She had been melancholy for a day or two and that morning had complained of pain in the left iliac region and great tenderness when the part was palpated. A feeling of suffocation ushered in the actual attack, followed by fixation of the pupils and then a well-marked tonic stage. The clonic stage was less marked and gradually passed into a condition of violent gesticulations combined with attempts to strike her head and injure those around her. This would continue until apparently she was thoroughly exhausted and then she would gradually become quiet and pass into another convulsion. The patient had been taking at one time and another bromides and the dragées antinerveuses de gélineau, but without, it seemed, much result.

The fact of the tongue not having been bitten, the kind of movements (as though with a purpose or object), the struggling with those who were restraining her, the length of each fit, the "something rising in her throat" which she described, and, last of all, the absence of any good result from 
the treatment of her previous condition led me to believe this to be a case of hystero-epilepsy.

CASE 2.-The patient was a neurotic-looking woman, twenty-two years of age, recently married, who had been weakened by an attack of influenza a short time before. During her school days she had had two or three "fits" of some kind, this being, so far as I could gather, when she was about the age of puberty. It was after a hard day's sightseeing at Versailles-a lot of the time having been devoted to looking at pictures-that the attack came on. She had gone to her room thoroughly worn out to get ready for dinner when she felt tremulous and very nervous, even going :30 far as to say that she had a feeling that "something dreadful" was going to happen. She sat down to rest a few moments, but had not been on the chair more than two or three minutes when with a shriek she fell on the floor and was seen to be convulsed. When I saw the patient she had rad one fit and another was just commencing. The tonic stage was well marked, the back and legs were extremely rigid, and the former was slightly arched. The pupils were dilated and fixed. This lasted for about 25 seconds and then the face began to twitch, the eyelids began to open and shut rapidly, and the to-and-fro movements of the arms and legs quickly followed. Frothy saliva escaped from the mouth, but was unmixed with blood and the face was but slightly livid. For about half a minute these movements were quite epileptic in character, just to-and-fro movements without aim or object, but gradually they began to lose this characteristic, she began to strike her head violently on the ioillow as though she wished to injure herself, and she kicked sut at us and attempted to bite our hands. She would pause in the midst of all this and remain quite still with her head a little on one side, as though listening (evidently aural hallucinations were present) and then become violent again. The duration of this stage varied from 15 to 25 minutes and then the patient would become quiet and remain in a semiconscious exhausted condition for a few moments, when the cycle would begin again. All the fits were much alike; the - only thing of note was that on one occasion, and one only, was there marked opisthotonos. I administered a hypodermic injection of hyoscine hydrobromate $\left(\frac{1}{75}\right.$ gr.), which - saused the fits to cease and produced five hours' sleep. On .awaking the patient was very emotional and far from well, out there was no return of the fits; her tongue had not been bitten and she spoke of having been "choked with something" -evidently "globus."

Hyoscine, we know, is most useful in cases of status epilepticus and in the convulsions associated with general paralysis of the insane; it appears to be of service also in this condition of hystero-epilepsy, and certainly it is much less tedious than the old chloroform method.

Ticehurst.

\section{A CASE OF PACHYDERMIA (VIRCHOW).}

Bz E. M. LIGHT, M.A., M.B. CAN'tab.

THE patient, a man, aged fifty-one years, consulted me in 1895 for a pain on the left side of the throat on swallowing his saliva-nothing else and no pain at any other time. The present symptom had lasted for three months and he gave a history of the same trouble two years previously. He had never noticed the presence of blood in his saliva. He was sspecially anxious to have the existing condition of his throat cleared up as his father and an uncle had died from cancer. For the last twenty-five years he had suffered from asthma which was worse in autumn, and on inquiry I found that his mother had suffered equally from the same complaint. He weighed 10st. 9lb. and had not lost flesh. On examination with the laryngoscope there was to be seen a distinct ulceration, owing to the break-down of the thickened parts, on the processus vocalis of the left vocal cord, completely corresponding to where he felt the pain and inconvenience. The neighbourhood of the spot was considerably congested. I advised him independently to see Sir Felix Semon, which he did, by whose kindness I received a letter verifying the above condition of the left vocal cord, enclosing a sketch, and stating the case to be one of pachydermia (Virchow). How the patient came by this rather rare affection it was impossible to say, as he lived quietly in the country, was not a great talker, and was moderate in what he drank as in everything else. No local treatment was advised except applications of cold externally (cold compresses at night) and sucking of ice, in order not to irritate still further the part. The importance of resting the roice and of the aroidance of irritants (dust, stale tobacco smoke, hot and peppered food and drinks, \&c.) was impressed upon him. Internally, iodide of potassium in 5-grain doses three times a day was prescribed for some time. In about three weeks he wrote to say that his throat was better and the irritation less, but that the medicine gave headache, so the dose was reduced to twice daily. Three weeks later he again wrote to say that he had no pain in the throat and felt quite well. He was advised to continue the iodide of potassium and after another period of six weeks he was again seen by Sir Felix Semon and myself and was pronounced cured. He is alive and well at the present time and has had no return of the affection.

This case is interesting from many points of view. A certain number of authorities, Schrötter among them, deny that a simple chronic laryngitis is ever capable of causing ulceration of the mucous membrane, its presence denoting the existence of specific lesions, tuberculous or syphilitic, and that when one sees lesions apparently ulcerative it is in reality a desquamated mass of epithelial cells or of mucus, without loss of subjacent substance. On the contrary, Störk, Schnitzler, and Heryng ${ }^{1}$ consider the existence of "catarrhal" ulcerations as an absolutely undeniable fact. Virchow has confirmed this opinion, his term "erosive" ulcerations denoting a number of simple erosions, as there is never extensive and deep loss of substance. Again, the clearness of outline of the ulcerations, the intense redness of the limiting mucous membrane, the raised appearance of the surface, the seat of the erosions on the internal surface of the cords, the absence of any previous localised infiltration, with the existence of an interarytenoid desquamation with irregular outlines, lead one to consider that the condition is not of bacillary origin, and the spontaneous cure of the erosions confirms this view.

According to Virchow pachydermia is only a chronic inflammation of the mucous membrane of the larynx, a lesion resulting either from a simple catarrh, tubercle, syphilis, or early cancer. The "diffuse" form of pachydermia is especially associated with abuse of alcohol or tobacco, the excessive use of the voice in the open air, or exposure to the inhalation of various forms of dust, while the nodular form is more closely associated with children, women of middle age employed as teachers, actresses, singers, or girls who have been badly taught to sing, and rarely with men.

The nature of the laryngeal affection indicated by the aspect, disposition, and seat of the lesions; the course of erents, age, sex, and mode of life of the patient; and the state of the nasal fossæ and pharynx. \&c., help to fix a diagnosis. The affection, though chronic and progressive and often rebellious to treatment, is curable, but often enough when one side gets better the other becomes affected.

Wilton-place, S.W.

\section{NOTE ON A MODIFICATION OF THE WEIGERT-PAL METHOD FOR PARAFFIN SECTIONS.}

BY E. E. LASLETT, M.B. VICT., B.Sc. LOND., HOLSE SURGEON TO THE LIVERPOOL ROYAL INFIRMARY.

So far as I am aware no mode of procedure has yet been published by which the Weigert staining method for nervous tissues can be applied to paraffin sections. For some time attempts were made to apply the method which is known in Schäfer's Histology as the Weigert-Pal process to paraffin sections by first fixing them on a slide and, after removal of the paraffin in the usual way, treating with Marchi's solution, followed by the acetic acid hæmatoxylin. This method was found to be unsatisfactory, as, although the nerve fibres were marked out in a more or less definite way, it was seen on close examination that they did not really stain in "ring fashion" at all. In sections stained

1 Hersng: Rerue de Larrngologie, ler Mai, 1885. Schnitzler : 1 Heryng: Rerue de Laryngologie, ler Mai,
Congrès International de Laryngologie de Paris, 1889. 